\title{
PRÉ-RESFRIAMENTO DE MAÇÃ (Malus domestica Borkh.), cv. FUJI, EM FUNÇÃO DA TEMPERATURA E VELOCIDADE DO AR ${ }^{1}$
}

\author{
MARIA IVETE DE FREITAS LOUZADA², IVAN SESTARI ${ }^{3}$, ARNO BERNARDO HELDWEIN4, AURI BRACKMANN ${ }^{5}$
}

\begin{abstract}
RESUMO - O objetivo do trabalho foi determinar o efeito de três velocidades e três temperaturas do ar, no pré-resfriamento de maçã, cv. Fuji, até $5^{\circ} \mathrm{C}$. Os tratamentos utilizados originaram-se da combinação de três temperaturas $\left(-1,-2\right.$ ou $\left.-3^{\circ} \mathrm{C}\right)$ e três velocidades do ar de resfriamento $\left(1,2\right.$ ou $\left.3 \mathrm{~m} \cdot \mathrm{s}^{1}\right)$. O decréscimo da temperatura dos frutos é maior e seu tempo de resfriamento diminui com o aumento da velocidade de $1 \mathrm{~m} . \mathrm{s}^{-1}$ para $3 \mathrm{~m} . \mathrm{s}^{-1} \mathrm{e}$ a redução da temperatura do ar de refrigerado de $-1{ }^{\circ} \mathrm{C}$ para $-3^{\circ} \mathrm{C}$; sendo o decréscimo da temperatura e o tempo de resfriamento das maçãs mais dependentes da velocidade do ar de refrigeração do que da temperatura obtida na entrada do túnel. Existe uma relação direta entre o decréscimo de temperatura dos frutos e a posição das caixas no túnel pré-resfriador. Com uma velocidade de $3 \mathrm{~m} \cdot \mathrm{s}^{-1} \mathrm{e}$ temperatura de $-3^{\circ} \mathrm{C}$ foi possível resfriar maçãs de 25 para $5^{\circ} \mathrm{C}$, em 40 minutos.
\end{abstract}

Termos de indexação: Temperatura de refrigeração, velocidade do ar.

\section{PRECOOLING OF APPLES (Malus domestica Borkh .) cv. FUJI, AS A FUNCTION OF THE TEMPERATURE AND VELOCITY OF THE AIR}

ABSTRACT - The objective of this study was to determine the relationship between three velocities and three temperatures of the air used to precool Fuji apples down to $5^{\circ} \mathrm{C}$. The treatments resulted from the combination of three temperatures $\left(-1,-2\right.$ or $\left.-3^{\circ} \mathrm{C}\right)$ and three air velocities $(1,2$ or $\left.3 \mathrm{~m} \cdot \mathrm{s}^{-1}\right)$. The results indicate that the fruit cooling rate increases and the time for cooling decreases with increases in air velocity from 1 to $3 \mathrm{~m} . \mathrm{s}^{-1}$ and decreases in air temperature from -1 to $-3^{\circ} \mathrm{C}$. The rate and time of cooling of the apples are much more dependent upon the velocity of the cooling air than the air temperature at the entrance. There is also a relationship between fruit cooling rate and the position of the boxes in the tunnel. With cooling air in the velocity of the $3 \mathrm{~m} \cdot \mathrm{s}^{1}$ and temperature of $-3^{0} \mathrm{C}$ it was possible to cool down apples from 25 to $5^{0} \mathrm{C}$ in 40 minutes.

Index terms: Air temperature, air velocity.

O pré-resfriamento é uma das mais importantes etapas póscolheita que consiste na remoção rápida de calor do campo dos frutos antes do armazenamento, processamento ou comercialização (Hardenburg et al., 1986). A maioria das câmaras de armazenagem não possui suficiente capacidade de refrigeração e nem o movimento de ar com velocidade suficiente para efetuar um resfriamento rápido dos produtos recém armazenados. Desta forma, o pré-resfriamento, geralmente, é uma operação separada e que necessita de equipamentos de maior capacidade de refrigeração.

O Brasil, apesar de ser um país tropical, dispõe de poucos préresfriadores comerciais. Além disso, pela falta de conhecimento dos produtores, o armazenamento ainda é feito de forma bastante precária e o pré-resfriamento dos frutos geralmente não é efetuado. Este fato, juntamente com a entrada de novas cargas ainda não resfriadas na unidade de armazenamento, faz com que o processo de resfriamento na câmara seja muito demorado e irregular, principalmente em função da oscilação da temperatura. Segundo Thompson et al. (1998), todos os produtos frescos podem ser resfriados com ar forçado, mas esse processo é comumente mais usado para frutas frescas e flores de corte. De acordo com Warrington \& Weston (1990), uma das vantagens do pré-resfriamento por ar forçado é que o processo pode realmente ser integrado na cadeia normal de manuseio pós-colheita. Dependendo do produto e da capacidade do ventilador, o método é quatro a dez vezes mais rápido que o resfriamento na câmara de armazenamento (Boyette et al., 1989).

A desvantagem do ar forçado é que o resfriamento é usualmente mais lento que os outros métodos, exceto em relação ao resfriamento na câmara, e pode causar excessiva perda de água em alguns produtos, em função, principalmente, da umidade e da velocidade do ar de resfriamento. Hardenburg et al. (1986) afirmam que a média da temperatura do produto durante o processo de pré-resfriamento segue o padrão em que a taxa de redução da temperatura está relacionada com a diferença de temperatura entre o produto e o ar de resfriamento. Há necessidade de mais pesquisas sobre a melhor utilização do pré- resfriamento com ar forçado, para as condições brasileiras, sendo pouco realizado devido ao desconhecimento das técnicas mais adequadas ou a falta de equipamentos apropriados. Nesse sentido, objetivou-se testar o efeito da temperatura e velocidade do ar no pré-resfriamento de maçãs, cultivar Fuji.

O experimento foi conduzido no Núcleo de Pesquisa em PósColheita do Departamento de Fitotecnia da Universidade Federal de Santa Maria (NPP/UFSM). Utilizou-se uma câmara frigorífica, onde foi montado um túnel para pré-resfriamento com ar forçado, com capacidade para comportar três caixas plásticas, cada uma contendo $22 \mathrm{~kg}$ de frutos. O túnel constou de uma caixa de 2,25m de comprimento, $0,63 \mathrm{~m}$ de largura e $0,35 \mathrm{~m}$ de altura. O fluxo de ar forçado através do evaporador, foi conduzido até a entrada do túnel por um ducto de $0,40 \mathrm{~m}$ de diâmetro e 1,0m de comprimento. Maçãs da cv. Fuji foram selecionadas e colocadas em 9 caixas plásticas. Após a classificação, as amostras foram deixadas por 12 horas em câmara regulada na temperatura de $26,6^{\circ} \mathrm{C}$ para homogeneização da temperatura dos frutos, a qual, no momento de serem levados ao túnel, ficou em torno de $25,0^{\circ} \mathrm{C}$. As amostras dos frutos utilizadas nas determinações foram constituídas de uma caixa de frutos. O experimento foi composto de 27 amostras experimentais de $22 \mathrm{~kg}$, decorrentes de nove tratamentos, com três repetições, avaliandose a combinação de três temperaturas $\left(-1^{\circ} \mathrm{C},-2^{\circ} \mathrm{C}\right.$ ou $\left.-3^{\circ} \mathrm{C}\right)$ e três velocidades do ar refrigerante $\left(1 \mathrm{~m} \cdot \mathrm{s}^{-1}, 2 \mathrm{~m} \cdot \mathrm{s}^{-1}\right.$ ou $\left.3 \mathrm{~m} \cdot \mathrm{s}^{-1}\right)$. A temperatura, estabelecida para cada tratamento, foi monitorada com termômetro digital, com sensor localizado na frente da primeira caixa. A velocidade do ar de resfriamento foi regulada pela abertura do defletor fixado na entrada do túnel e monitorada por um anemômetro digital, colocado após a $3^{\text {a }}$ caixa. Foram utilizados dois termômetros digitais portáteis com cinco sensores cada, inseridos a $2 \mathrm{~cm}$ de profundidade, os quais foram utilizados para medir a temperatura na polpa das maçãs em diferentes posições no interior das 3 caixas, bem como a temperatura do ar na entrada e saída do túnel. As temperaturas dos 10 sensores foram checadas a cada cinco minutos, até a temperatura da polpa atingir cerca de $5,0^{\circ} \mathrm{C}$, quando se encerrava o tratamento.

\footnotetext{
(Trabalho 069/2003). Recebido: 22/12/2003. Aceito para publicação: 24/10/2003.

${ }^{2}$ Enga $^{\mathrm{a}}$ Agra MSc. Prefeitura Municipal de Caçapava do Sul, E-mail: smaic@farrapo.com.br

${ }^{3}$ Eng $^{\circ}$ Agr $^{\circ}$ Departamento de Fitotecnia, NPP/UFSM, E-mail: isestari@bol.com.br

${ }^{4}$ Orientador Prof. Titular do Departamento de Fitotecnia, CCR/UFSM, E-mail: heldwein@creta.ccr.ufsm.br

${ }^{5}$ Co-orientador, Prof. Adjunto do Departamento de Fitotecnia, CCR/UFSM, 97105-900, Santa Maria-RS, E-mail: brackman@ccr.ufsm.br. Autor para correspondência.
} 
Os resultados de diminuição da temperatura das maçãs estão representados nas curvas de variação da temperatura com o tempo (Figura 1). Ressalta-se que nem sempre foi possível manter a temperatura do ar de refrigeração prevista para o tratamento no início do processo. Isso ocorreu porque enquanto era instalado o tratamento, a temperatura no interior da câmara fria aumentava devido a ventilação estar desligada, a entrada e saída de pessoas, após concluírem o tratamento. De acordo com Yun et al. (1995), o calor a ser retirado é a soma do calor liberado pelo produto, pelo ventilador, das embalagens, das pessoas e da respiração do produto. Observando-se as curvas de resfriamento verifica-se que (Figura 1) o aumento da velocidade do ar refrigerante é mais eficiente que a redução da temperatura desse ar. Portanto, o tempo de resfriamento é mais dependente da velocidade do que da temperatura do ar de entrada no túnel. Observa-se que ocorreram diferenças no tempo de resfriamento em função da velocidade do ar, a qual variou de
35 a 50 minutos para a maior velocidade $\left(3 \mathrm{~m} \cdot \mathrm{s}^{-1}\right)$ e 75 a 85 minutos para a menor velocidade $\left(1 \mathrm{~m} \cdot \mathrm{s}^{-1}\right)$. Esta variação de tempo ocorreu em virtude da temperatura do ar refrigerante. Isso confirma a tendência de que a maior velocidade do ar de resfriamento implica em um resfriamento dos frutos mais rápido. Não houve alteração considerável no tempo de resfriamento proporcional às temperaturas do ar utilizadas (Figura 1). $\mathrm{O}$ tempo aproximado de resfriamento variou de 35 a 80 minutos, para a temperatura mais baixa $\left(-3^{0} \mathrm{C}\right)$ e de 40 a 85 minutos, para a mais alta ($1{ }^{\circ} \mathrm{C}$ ), conforme a velocidade do ar utilizada (Figura 1). Este resultado está de acordo com Thompson et al. (1998), que afirmam que o aumento no fluxo de ar reduz o tempo de resfriamento. Na temperatura de $-1{ }^{\circ} \mathrm{C}, \mathrm{o}$ resfriamento foi maior nos primeiros 5 minutos, com a velocidade de $2 \mathrm{~m} \cdot \mathrm{s}^{-1} \mathrm{em}$ relação a $3 \mathrm{~m} \cdot \mathrm{s}^{1} \mathrm{o}$ que pode ser atribuído às diferentes posições das maçãs na caixa, nas quais foram colocados os sensores ou outro erro experimental.
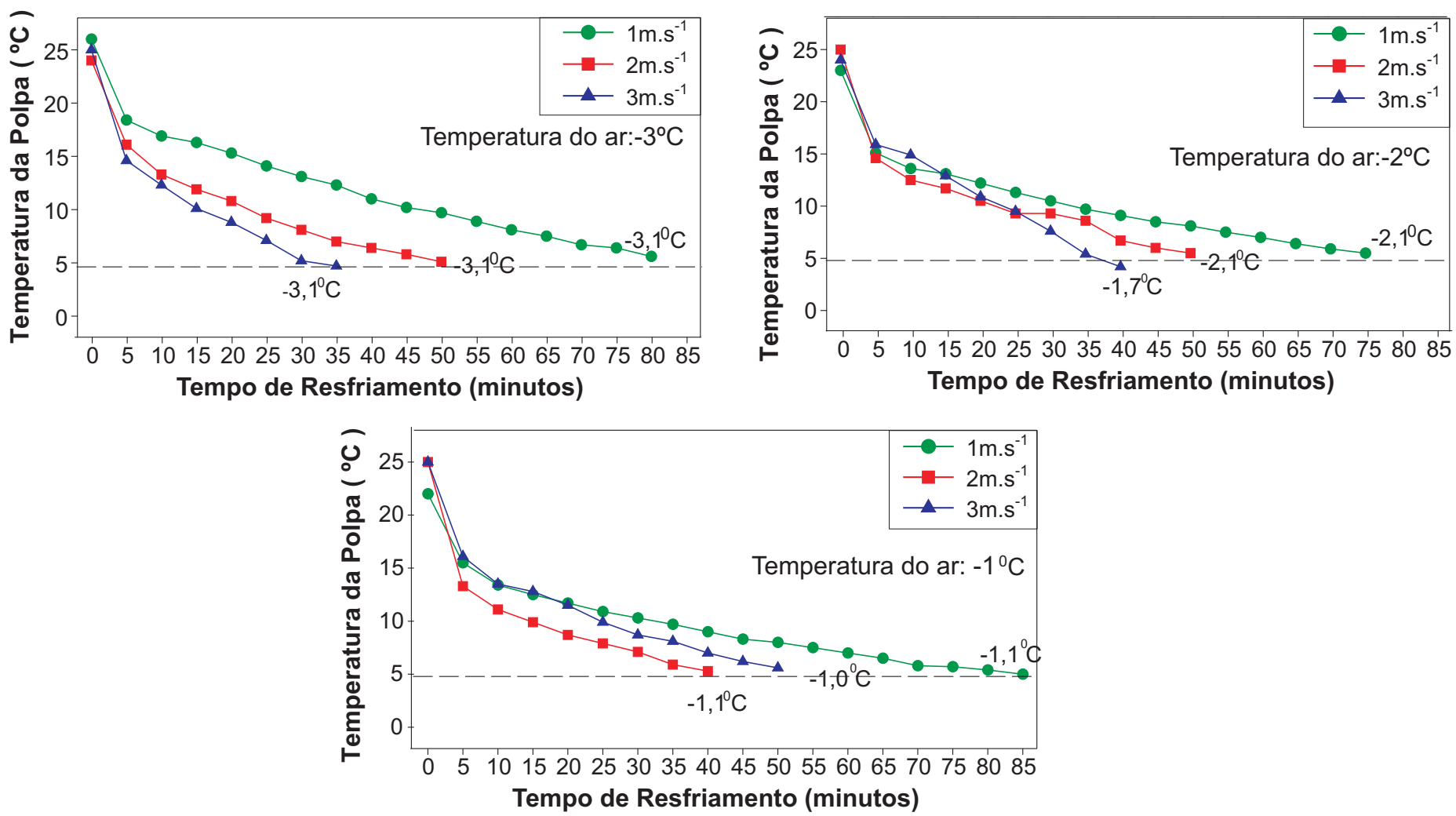

FIGURA1 - Temperatura e tempo de resfriamento de maçã, cv Fuji, em função da velocidade e temperatura do ar no túnel de pré-resfriamento. Santa Maria, RS, 2001.

O decréscimo da temperatura dos frutos é maior e o tempo de resfriamento diminui com o aumento da velocidade do ar de $1 \mathrm{~m} \cdot \mathrm{s}^{-1}$ para $3 \mathrm{~m} . \mathrm{s}^{-1}$ e a redução da temperatura do ar refrigerado de $-1^{\circ} \mathrm{C}$ para $-3^{\circ} \mathrm{C} . \mathrm{E}$ que o decréscimo da temperatura e o tempo de resfriamento são mais dependentes da velocidade do ar de refrigerado do que da temperatura do ar na entrada do túnel pré-resfriador.

\section{REFERÊNCIAS BIBLIOGRÁFICAS}

BOYETTE, M. D.; WILSON, L. G.; ESTES, E.A. Introduction to proper post-harvest cooling and handling methods [ on line]. Disponível na Internet via www. URL: http:// www.2nasv. edu/eos/service/pae/ www/..ion/publicat/posthaving. Arquivo capturado em 19 de dezembro de 1998. The North Carolina Extension Service, NCSU-
BAE. PublicaçãoAG.414-1.1989.

HARDENBURG, R. E.; WATADA, A. E.; WANG, C. Y. The commercial storage of fruits, vegatables and florist nursery stocks. Washington: USDA, 1986. 136p. (Agriculture Handboock, n.66).

THOMPSON, J. F.; RUMSEY,T.R.; MITCHEELL, F.G Forced-Aircooling. In: COMERCIAL cooling of fruits, vegetables, and flowers. University of California. Division of agriculture and natural science, 1998. p.28-32. (Publicacion, 21567).

WARRINGTON, I.J.;WESTON, GC. Kiwifruit: science and management. Auckland: Ray Richards/ New Zealand Society for Horticultural Science, 1990. 576p.

YUN, H.S.; CHO, YY. K.; PARK. K.K. Resistance to airflow through fruits and vegetables in bulk. Journal of the Korean Society for Agricultural Machinery, v.20, n. 4, p.333-342, 1995. 